\title{
João Soares Coelho, Picandon e um jogo de avessos: sobre "vedes, picandon, soo maravilhado"*
}

Paulo Roberto Sodré Universidade Federal do Espírito Santo

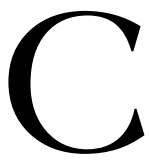

onviria perguntar, diante das atuais investigações sobre a sátira galego-portuguesa - como as de Jesus Montoya Martínez (1989), Graça Videira Lopes (1994), Giulia Lanciani e Giuseppe Tavani (1995), Américo António Lindeza Diogo (1998), Benjamin Liu (2004) e Vicenç Beltran (2005), para referir apenas os mais recentes -, como ler as cantigas de escárnio e maldizer; quais seriam os limites de seu caráter lúdico e crítico; qual o sentido, a abrangência e o efeito do uso dos equívocos que nelas encontramos.

Responder a essas questões, sabe-se, implica não apenas no estudo atento da Arte de trovar, das teorias sobre riso, sátira e comicidade, de um conjunto de textos que, contemporâneos aos trovadores, podem nos ajudar a compreender melhor a cultura peninsular dos séculos XII, XIII e XIV, mas implica, sobretudo, na releitura das cantigas. Nesse sentido é que talvez seja producente revermos a tenção entre João Soares Coelho e Picandon, “-Vedes, Picandon, sôo maravilhado" (CV 1021), cotejando-a com o que se tem discutido mais recentemente sobre a produção satírica galego-

\footnotetext{
* Trabalho inédito apresentado no XXII Congresso Internacional da Associação Brasileira de Professores de Literatura Portuguesa, na Faculdade de Letras da Universidade Federal da Bahia, em Salvador, de 13 a 18 de setembro de 2009.
} 
portuguesa. Cremos que a cantiga parece revelar mais do que vem sendo detalhado pela crítica, normalmente fascinada pelo que ela oferece de provençalismos na linguagem e de dados para o mapeamento do itinerário poético de Coelho e das passagens e contatos de trovadores estrangeiros em terras peninsulares.

- Vedes, Picandon, soo maravilhado eu d' En Sordel, [de] que ouço entenções muitas e boas e mui boos sões, como fui en teu preito tan errado: pois non sabedes jograria fazer, por que vos fez per corte guarecer? Ou vós ou el dad' ende bon recado.

- Joan Soárez, logo vos é dado

e mostrar-vo-lo-ei en poucas razōes: gran dereit' ei de gaar [muitos] does

e de seer en corte tan preçado como segrel que diga: "Mui ben m' es en cançós e cobras e serventes", e que seja de falimen guardado.

- Picandon, por vós vos muito loardes, non vo-lo cataran por cortesia, nen por entrardes na tafularia, nen por beverdes nen por pelejardes:

e, se vos esto contaren por prez, nunca Nostro Senhor tan cortês fez como vós sodes, se o ben catardes.

- Joan Soárez, por me deostardes, non perç' eu por esso mia jograria; e a vós, senhor, melhor estaria d' a tod' ome de segre ben buscardes:

ca eu sei cançōes muitas e canto ben

e guardo-me de todo falimen

e cantarei, cada que me mandardes. 
- Sinher, conhosco-mi-vos, Picandon,

e do que díxi peço-vos perdon

e gracir-vo-l' ei, se mi perdoardes.

- Joan Soárez, mui de coraçon

vos perdoarei, que mi dedes don

e mi busquedes prol per u andardes. ${ }^{1}$

Na primeira estrofe, Coelho acusa Picandon de má “jograria”, de que se defende o jogral a serviço de Sordello da Goito, alegando ser muito bom em "cançós e cobras e serventés", sem cometer falha. $\mathrm{Na}$ finda, os dois versos iniciais de Coelho sugerem justamente que o trovador português sabia, entretanto, das qualidades de Picandon: "Sinher, conhosco-mi-vos, Picandon/ e do que díxi peço-vos perdon”. O trovador português lança mão do avesso das qualidades do jogral, "deostando-as" ou deformando-as para efeito de seu jogo satírico. Resta saber a razão de João Soares Coelho ter se desculpado pelo deostar na própria cantiga, o que não sói ocorrer em outras cantigas. ${ }^{2}$ Segundo leitura de Vicenç Beltran, João Soares estranhou que Sordello, de gosto tão refinado, confiara nos parcos dotes artísticos de seu jogral; chama atenção para o segundo verso, “eu d' En Sordel, [de] que ouço entençôes", o que sugere a presença imediata da arte do trovador provençal. Essa sugestão enseja a investigação de Beltran sobre a data e o local da cantiga.

Desde os minuciosos estudos de Carolina Michaëlis de Vasconcelos, investiga-se sobre Picandon e sua presença no ambiente trovadoresco peninsular. Em sua tese de doutorado, de 2001, Ângela Correia expôs uma súmula das informações ainda provisórias sobre os itinerários de João Soares Coelho e de seu suposto encontro com o jogral de Sordello. Dois períodos principais são observados por Correia: o primeiro, a serviço do infante

${ }^{1}$ LAPA, 1995, p. 163. Cf. edição de Graça Videira Lopes (2002, p. 254-255). 2 TAVANI, 1988, p. 383. Graça Videira Lopes também destaca a idiossincrasia da tenção: "A diferença, nesta tenção, está, por um lado, nos numerosos provençalismos que Picandon utiliza nas suas respostas, e por outro, no tom cortês final que João Soares Coelho adopta" (2002, p. 254). 
Fernando de Serpa, "mais itinerante e pródigo em contactos internacionais com interesses literários, um segundo, ao serviço da corte régia de Afonso III, em que as obrigaçôes administrativas no reino português o terão proporcionado menos". 3

Por sua vez, revisando os resultados expostos sobre a questão, inclusive os da tese de Correia, Vicenç Beltran ${ }^{4}$ deduz que Sordello deve ter saído da Itália entre 1228-1229, estando primeiro com Savaric de Mallen e talvez em outras regiōes da Gália, para se dirigir a Castela e Leão em busca do apoio de Fernando III. Com este viajou para Sabugal, na primavera de 1231, onde e quando, na corte portuguesa, deveria estar João Soares Coelho; logo, no início de 1232, o trovador Sordello poderia ter feito a peregrinação jacobéia com o rei.

Para efeito do que pretendemos discutir neste trabalho, importam duas questóes fundamentais: 1. a data da tenção com Picandon teria ocorrido entre o final da década de 20 e início da de 30; 2. a hipótese de Elsa Gonçalves de que a figura de Picandon seria inventada, "sendo o seu nome apenas uma peça num jogo vocabular e o texto, consequentemente, uma tenção fictícia”. ${ }^{5}$ No caso desta idéia de Gonçalves, ainda que a figura do jogral seja inexistente, o jogo escarninho de Coelho a tentar picar Sordello, em sua capacidade de indicar um jogral, e a se desculpar depois pela brincadeira é o que nos interessa investigar. Comentada a cantiga a partir de seu ponto nuclear - o "deostar" e a revelação do jogo satírico pelo trovador português -, vejamos o que a noção de jugar de palabra, exposta na segunda de Las siete partidas de Afonso X, poderia nos oferecer de chave para a leitura da tenção.

Uma das alternativas para a apuração de certos aspectos da produção trovadoresca, tanto no campo geral da cultura e da sociedade, como no particular da poesia e das mentalidades, pode ser a investigação de

${ }^{3}$ CORREIA, 2001, p. 78.

${ }^{4}$ BELTRAN, 2005, p. 64.

${ }^{5}$ CORREIA, 2001, p. 69. 
documentos como o código jurídico organizado por Afonso X. Nos estudos filológicos e literários, Carolina Michaëlis de Vasconcelos (1896) e Ramón Menéndez Pidal (1942) fundamentaram nas leis das Partidas suas opiniōes a respeito da corte trovadoresca peninsular. Em investigaçōes mais recentes, Jesús Montoya Martínez (1991), Rafael M. Mérida (1993) e Benjamin Liu (2004) voltaram às leis afonsinas, procurando observar sua relação com a sátira e a organização da corte.

Dos códigos jurídicos mais completos desse período, Las siete partidas estão longe de ser "uma mera seqüência de normas", sendo ao mesmo tempo um tratado moral, espelho do tempo, projeto de reforma social, monumento da arte literária, como observou Alfonso D'Agostino. ${ }^{6}$ Considerada uma súmula de seu projeto jurídico, anunciado e preparado nos anteriores Especulo (1255), Fuero real (1255) e Setenario (1256), as Partidas ${ }^{7}$ condensam um ideário de jurisdição que abraça todas as esferas de um senhorio de rei e de candidato a imperador, 8 o que as torna, segundo Azucena Palácios Alcaine, "uma magnífica porta para o conhecimento de uma época".

As Partidas ${ }^{10}$ foram produzidas sob a direção e os auspícios diretos de Afonso X, provavelmente entre 1256 e $1265,{ }^{11}$ quando já haviam sido

${ }^{6}$ D'AGOSTINO, 2001, p. 745.

${ }^{7}$ Embora as datações não sejam muito consensuais, de acordo com Antonio Ballesteros Beretta (1984, p. 356 et seq.), Azuzena Palácios Alcaine (ALFONSO X, 1991, p. xv) e Alfonso D’Agostino (2001, p. 743), são essas as datas aproximadas.

${ }^{8}$ Como se sabe, o Sábio arquitetou as Partidas, tendo em vista principalmente sua chance de coroar-se senhor do Sacro Império Romano. Devido a essa possibilidade, seu código jurídico ganhou dimensões para além do reino local de Leão e Castela.

9 PALÁCIOS ALCAINE, 1991, p. xx.

${ }^{10}$ Embora outros códigos jurídicos sejam observados neste estudo, as Partidas são o principal documento para esta investigação.

${ }^{11}$ Sobre o período de produção das Partidas, cf. Otero (1993-1994) e O’Callaghan (2001). 
postos em circulação antecendentes importantes como o Especulo, o Fuero real e o Setenario. Por incorporarem-nos e ampliarem seu escopo legal, as Partidas estabeleceram a fundação do sistema jurídico do reino medieval de Leão e Castela e, mais tarde, da Espanha moderna e dos países sob sua colonização. ${ }^{12}$ Sete livros ou "partidas" compõem a obra: a Primeira trata da Igreja medieval, em que se regula a vida dos clérigos e leigos; a Segunda, da vida dos reis e de seus oficiais; na Terceira, expõem-se a jurisprudência, os advogados e seu trabalho; na Quarta, trata-se das relaçōes domésticas e casamentos; na Quinta, regula-se o mundo do comércio, do mar, e dos contratos; na Sexta, discorre-se sobre os testamentos, e na Sétima, sobre os marginais, os crimes e as penalidades. Um livro como esse, riquíssimo em vários aspectos, não passaria despercebido aos pesquisadores.

Em 1991, Aurora Juarez Blanquer e Antonio Rubio Flores publicaram a edição do manuscrito 12.794 da Biblioteca Nacional de Madrid da "Segunda Partida”, em que o Sábio discorre justamente sobre três fundamentos do poder terreno, leigo: governo e papel do rei, defesa e arte da guerra, e educação como recurso central e garantia sagrada do governo. ${ }^{13}$ Nessa "Partida" é que deparamos informaçōes importantes para a concepção de convívio cortesão, fablar en gasaiado, e de entretenimento por meio de burlas ou jugar de palabras.

Em geral, vários itens a respeito da educação e da política são tratados nessa Partida. Além do Título IV, por exemplo, em que se expóe o conceito de palavra e seus tipos: conveniente, soberba, minguada (lacônica ou mentirosa), inconveniente (lisonjeadora ou maledicente) e caçurra (feia ou chula), no Título V, indicam-se as obras do rei como exemplo e espelho. $\mathrm{O}$ aspecto que interessa pontualmente encontra-se no Título IX ("Qual deve el rey ser a sus ofiçiales, e a los de su casa e de su corte, e ellos a el"), composto de trinta leis, em que se vislumbram, ao menos teoricamente,

${ }^{12}$ Robert Burns comenta a duração das Partidas inclusive nas leis norte-americanas (2001).

${ }^{13}$ BURNS, 2001, v. 2, p. ix. 
a função e os tipos de oficiais (capelão, chanceler, conselheiro, juiz etc.); ${ }^{14}$ o conceito de corte e palácio e, no que diz respeito a sua organização, as normas de conduta para o entretenimento do rei e dos que o freqüentam.

Em seu estudo sobre teoria educativa da "Segunda Partida", Jesús Montoya Martínez elucida aspectos importantes, em especial, o que concerne à noção de literatura como um jogo dentre os outros apreciados pelo rei. Importa notar que as fontes possíveis dessa "Partida" abrangem Cícero e John of Salisbury, além de Isidoro de Sevilla, o que contorna as leis de um culto aparato doutrinário, etimológico e antigo.

Chave para a compreensão do que aqui se discute - a cortesia de João Soares Coelho ao final de seu escárnio contra Picandon - é o momento em que o rei se reúne com os seus, na intenção de gasaiado, isto é, o gozar "la alegría o el pasatiempo placentero en compañía". ${ }^{15}$ Nesse ambiente, entram os trovadores, jograis, menestréis e soldadeiras, com a finalidade de contar histórias ou apresentar cantigas, tocar a cítola ou dançar, agradar e receber os dons, caso sua competência, aquilatada por meio da capacidade de os trovadores obedecerem a uma expectativa de discurso sancionado pela tradição, seja aprovada.

Para garantir o respeito à convivência em palácio - onde "conviene que non sean y dichas otras palabras synon verdaderas e complidas e apuestas" -, o Rei tratou de regularizar as três principais circunstâncias sociais palacianas: a deliberação dos pleitos, as refeições e o fablar en gasaiado: "E quando es para fablar en manera de gasaiado, asy commo para departir o para rretraer, o para jugar de palabra, ninguna destas non se deve de fazer synon commo conviene". ${ }^{16}$ Neste fablar en gasaiado, três maneiras de conversação ganham definições: o departir, o retraer e o jugar de palabra.

${ }^{14}$ Esses dados ocupam da lei I à XXVI (ALFONSO X, 1991, p. 83-99).

${ }^{15}$ MONTOYA MARTÍNEZ, 1991, p. 371.

${ }^{16}$ ALFONSO X, 1991, p. 101. 
A maneira de departir, isto é, "falar, conversar": 17 "que non mengue el seso al omne por el, asy commo ensannandose: ca esta es cosa que saca mucho ayna de su siesto: mas conviene que la faga de guysa que se acresçiente el entendimiento por el, fablando en las cosas con razón para allegar a verdat dellas". ${ }^{18} \mathrm{O}$ importante na conversação seria a discussão de temas, sem que a ira e a perda da razão se fizessem presentes, tornando o colóquio aprazível e polido, além de moralmente fecundo.

Na Lei XXX do Título IX da "Partida Segunda", "Quantas cosas deven ser catadas en el rretraer", Afonso X destaca as duas outras maneiras de fablar en gasaiado, rretraer jugar de palabra, coincidentes estas duas em um aspecto: o caráter lúdico e literário. O início da Lei é dedicado ao rretraer; trata-se de narrar ou referir façanhas ou coisas "como fueron, o son o pueden seer". ${ }^{19}$

Do "jugar de palabra” se transcreve a lição de Aurora Juarez Blanquer e Antonio Rubio Flores:

(...) E en el juego deven catar que aquello que dixieren sea apuestamente dicho, e non sobre aquella cosa que fuere en aquel lugar a quien jugaren, mas a juegos dello, commo sy fuere cobarde dezirle que es esforçado, jugarle de cobardia; ${ }^{20}$ e esto debe ser

MAGNE, 1944, p. 161. Além desse sentido, Magne apresenta outros, já apontados por Carolina Michaëlis de Vasconcelos no "Glossário" do Cancioneiro da Ajuda (1990, v. 1, p. 26): "falar mal, censurar, murmurar de; distinguir, extremar, demarcar; dividir, separar, afastar” (MAGNE, 1944, p. 161). Herbert Allen Van Scoy (1986) não inclui o verbo em seu dicionário; Aurora Juarez Blanquer cita apenas a definição do termo que consta na própria partida (ALFONSO X, 1991, p. 429). Para Rodrigues Lapa, há ainda a acepção de "dizer, julgar, sentenciar; discutir, altercar; tirar, afastar (relativamente a uma doença)" (1995, p. 316).

${ }^{18}$ ALFONSO X, 1991, p. 101.

${ }^{19}$ ALFONSO X, 1991b, p. 101-102.

${ }^{20}$ Observe-se que na edição de Gregório López o exemplo é desdobrado ("como ?i fuere couarde: decir le q es esforzado: e al esforzado jugar le de couardia"), o que não acontece nessa. 
dicho de manera que aquel a quien jugaren non se tenga por denostado, mas quel ayan de plazer, e ayan de rreyr dello tan bien el commo los otros que lo oyeren. E otrosy el que lo dixiere que lo sepa bien rreyr en el lugar do conveniere, ca de otra guysa non serie juego onde omne non rrye; ca sin falla el juego con alegria se deve fazer, e non con sanna nin con tristeza. Onde quien se sabe guardar de palabras sobejanas e desapuestas, e usa destas que dicho avemos en esta ley, es llamado palaçiano, porque estas palabras usaron los omnes entendidos en los palaçios de los Reyes mas que en otros lugares; e ally rresçebieron mas onrra los que las sabien: e aun lo encaresçieron mas los omnes entendidos, ca llamavan antiguamente por cavalleros a los que esto fazien, e non era syn rrazon; ca pues que el entendimiento e la palabra estranna al omne de las otras animalias, quanto mas apuesta la a e mejor, tanto es mas omne. $\mathrm{E}$ los que tales palabras usaran e sopieren en ellas avenir, develos el Rey amar e preçiar, e fazer mucha de onrra e de bien; e los que se atrevieren a fazer esto non seyendo sabidores dello, syn lo que se mostrarien por atrevidos e por nesçios, deven aun aver por pena seer alongados de la corte e del palaçio. ${ }^{21}$

O ponto difícil e fundamental do trecho está nessa passagem: "E en el juego deven catar que aquello que dixieren sea apuestamente dicho, e non sobre aquella cosa que fuere en aquel lugar a quien jugaren, mas a juegos dello, commo sy fuere cobarde dezirle que es esforçado, jugarle de cobardia”: o que significariam precisamente a expressão "a juegos dello" e o exemplo "commo sy fuere cobarde dezirle que es esforçado, jugarle de cobardia"?

Jesús Montoya Martínez ${ }^{22}$ dedicou atenção a esse trecho da "Segunda Partida", primeiramente no artigo "Caracter lúdico de la literatura medieval (A propósito del 'jugar de palabra'. Partida Segunda, tít. IX, ley XXIX)”, de 1989, e, no estudo "Teoria educativa", de 1991, mais sintético do que o primeiro, mantendo, no entanto, as mesmas conclusões iniciais.

\footnotetext{
${ }^{21}$ ALFONSO X, 1991b, p. 101-102.

${ }^{22}$ Outros autores lançaram mão do trecho em análise, mas sem discuti-lo propriamente. Cf. Benjamin Liu (1998, p. 45).
} 
No artigo, o autor espanhol compara as duas concepções de jogo nas partidas "Primeira", negativa e censurada, e "Segunda", valorizada e incentivada. ${ }^{23} \mathrm{Em}$ seguida, passa a tratar do jogo de palavras, uma das modalidades de jogo da corte peninsular. Eis a paráfrase de Martínez do trecho difícil sobre o jugar de palabras:

En el juego - de palabra, se entiende - deve catar, que aquello que dixere, que sea apuestamente dicho, e non sobre aquella cosa que fuere en aquel, con quien jugaren, mas aviessas dello; como si fuera covarde, decirle que es esforzado, e al esforzado jugarle de covardia. ${ }^{24}$

[No jogo - entenda-se, o de palavra - deve-se observar que aquilo que se disser seja adornadamente dito, e não sobre aquela coisa \{o defeito\} que estiver naquele com quem se jogar \{e não diretamente sobre o defeito do visado da sátira\}, mas pelo avesso; como se fora covarde, dizer-lhe que é esforçado, e ao esforçado jogar com sua covardia ]. (Tradução nossa)

Montoya Martínez traduz uma das expressões-chave, "mas a juegos dello" para "mas aviessas dello", dando a entender, a princípio, que o jogo se faria pela oposição às qualidades do visado. Entretanto, nesse ponto se dá o problema de leitura. Para Montoya, o exemplo dado pelo Sábio é negativo, ou seja, ele deduz que não se deve brincar com o covarde, chamando-o, por equívoco, de valente, nem vice-versa:

Verdad y estética son por tanto las exigencias requeridas para este juego. Al cobarde no se le puede jugar de esforzado, ni al esforzado y valiente de cobarde, pero cualquiera de ellos puede tener unos rasgos

\footnotetext{
23 "La palabra puede herir y aun matar moralmente, constituyendo al hombre en cazador del diablo, como lo dice la Partida Primera. Pero también puede distender el ánimo y causar alegría y placer, como se deduce de la Partida Segunda, aunque esto último se logra siempre que se observen ciertas normas relativas a la estilística y a la ética" (MONTOYA MARTÍNEZ, 1989, p. 438). ${ }^{24}$ MONTOYA MARTÍNEZ, 1989, p. 438.
} 
morales que pueden ser hábilmente deformados. La clave está en encontrarlos y expresarlos convenientemente. ${ }^{25}$

[Verdade e estética são portanto as exigências exigidas para esse jogo. Ao covarde não se pode jogar de esforçado, nem ao esforçado e valente de covarde, mas qualquer deles pode ter traços morais que podem ser habilmente deformados. A chave está em encontrá-los e expressa-los convenientemente]

A desconfiança sobre essa leitura de Montoya Martínez surge no que parece ser uma contradição, em outro trecho de seu artigo. Afirma ele: "El juego como burla no tiene otra finalidad que el ridículo, poner en evidencia alguna cualidad, deformándola, sacarle partido a alguna situación ambigua, jugar con el doble sentido de las palabras". ${ }^{26}$ Não resulta convincente a dedução do autor espanhol, na medida em que qualquer uso de um "rasgo moral que possa ser habilmente deformado" recairia no mesmo problema de jogar, como no exemplo da covardia ou valentia. Se entender-se "rasgo moral" como qualquer qualidade do visado que possa vir a ser motivo de riso, que diferença haveria, para alguém da corte, entre covardia, avareza, descortesia, miopia, sensualidade, feiúra, maus modos, incompetência etc.? Ou melhor, que "rasgo moral" poderia ser tido como mais ou menos perigoso para uma sessão de escarnecimento por meio de jogo de palavra no palácio?

Martínez lê, portanto, o trecho do exemplo - "como si fuere cobarde, decirle que es esforzado, y al esforzado, jugarle de cobardía” - como o que não se deve fazer, quando, talvez, parece ser o contrário, isto é: no jogo devem cuidar que aquilo que disserem seja apropriadamente/bem compostamente dito, e não [diretamente] sobre aquela coisa [o defeito do visado] que estiver naquele lugar com quem jogarem, mas a jogos dele; ou seja, se ele for covarde, [devem] dizer-lhe que é esforçado, e ao esforçado, jogar com a covardia. O jogo, o avesso, ou seja, o equívoco estaria justamente na surpresa de os ouvintes e o próprio visado perceberem a brincadeira do

${ }^{25}$ MONTOYA MARTÍNEZ, 1989, p. 438. Itálicos acrescentados.

${ }^{26}$ MONTOYA MARTÍNEZ, 1989, p. 440. Itálicos acrescentados. 
jogo dos contrários. Nisso estariam a conveniência e a boa composição da cantiga: não dizer ao covarde que é covarde, nem ao sodomita que é sodomita, mas jogar com seu avesso, se isso fosse conveniente ao trovador e à corte: um seria valente; o outro, heterossexual.

Esse jogo de avesso é que parece estar subjacente à tenção de Coelho e Picandon. Coelho inicia uma tenção provocadora com Picandon - ou com o próprio Sordello, se levarmos em conta a hipótese de Elsa Gonçalves - já sabendo de antemão que a má "jograria" seria uma "razon" contrária às reconhecidas qualidades do jogral e de seu trovador. Isso explicaria a inesperada finda:

- Sinher, conhosco-mi-vos, Picandon,

e do que díxi peço-vos perdon

e gracir-vo-l' ei, se mi perdoardes.

Tal estratégia de sátira parece ser utilizada nas diversas cantigas dirigidas a Lourenço, para deostar seu trobar. Joaquim Ventura afirma, a esse propósito, que

os ataques contra trobadores e xograis (exclúo os ataques de tipo político) non podem ser tomados como proba de sinceridade (imposible en xeral na lírica da Idade Media) senón mais ben como um xogo - cruel ás veces, isso si - entre colegas ou entre señor e asalariado, frecuentadores dos mesmos circuitos de actuación. ${ }^{27}$

Não fosse assim, não teria o jogral cantigas de qualidade - como afiança seu editor, Giuseppe Tavani, ${ }^{28}$ nem estaria ele, passe a evidência, entre os poetas dos cancioneiros; sequer teria sido acolhido "en cas d'el rei", se considerar-se que "los que se atrevieren a fazer esto [jugar de palabras] non

VENTURA, 1993, p. 535. Itálicos do autor. Diante da ausência de apelido nas apóstrofes a Lourenço - o que não ocorre com outros jograis -, Ventura indaga se isso não seria uma demonstração da alta consideração que os trovadores lhe tinham (VENTURA, 1993, p. 543).

${ }^{28}$ LANCIANI; TAVANI, 1993, p. 425-427. 
seyendo sabidores dello, syn lo que se mostrarien por atrevidos e por nesçios, deven aun aver por pena seer alongados de la corte e del palaçio". ${ }^{29}$ É presumível que a tenção entre Coelho e Picandon corrobore a situação e a estratégia satírica deduzida da Lei XXX do Título IX da "Partida Segunda", de que a série de cantigas contra Lourenço e outros poetas, sobretudo, nas tenções de tema literário, seriam ilustrações interessantes.

Examinar esse ponto da lei é fundamental, a despeito de ser arriscado, porque dele se pode depreender um dos traços principais da sátira galegoportuguesa, não suficientemente desenhada na Arte de trovar. Como deveria ser feito o escarnecer? Que relação haveria entre o jugar de palabras e o equívoco tão disputado nas cantigas de escárnio e maldizer? Qual seria o grau de "verdade" das "acusações" e "denúncias", já posto em relatividade por Menéndez Pidal a propósito da cantiga de Afonso X, "Pero da Pont' á feito gran pecado", em que acusa Pero da Ponte de homicida e plagiário?

Se não deveria haver ira nem tristeza no entretenimento palaciano, e se a maior qualidade de um jugar de palabra estaria na capacidade de seu autor fazer-se ouvir prazenteiramente - ou seja, com cantigas bem talhadas, bem compostas e bem cantadas, além de convenientes -, as cantigas escarninhas, então, poderiam ser lidas não como críticas ou denúncias excetuando-se, por certo, as sátiras morais e políticas -, mas como jogos de espelhos apenas?

Podemos supor que o jogo ou equívoco prescrito na lei e utilizado pelos trovadores estaria não apenas no plano retórico da palavra ambígua, mas também no plano da deformação pelo avesso de uma dada situação, de um rasgo moral ou de uma qualidade de um cortesão. Em outras palavras, o equívoco se manifestaria tanto no plano do texto (jogo de palavras stricto sensu) como no plano do contexto (situação posta pelo avesso).

Embora o nome dos gêneros não apareça no trecho da lei XXX, não é difícil deduzir que se trata das cantigas escarninhas, tipo textual voltado para o riso, cuja sinonímia talvez inclua a expressão jugar de palabra usada por Afonso X na lei. Ao configurar os limites do jogo, o rei contorna a

${ }^{29}$ ALFONSO X, 1991b, p. 102. 
cantiga satírica, enfatizando e justificando um aspecto que aparecerá apenas classificatoriamente e no aspecto eminentemente retórico (equivocatio) na Arte de trovar: $:^{30}$

Se na poética galego-portuguesa o que importa é enfatizar que a cantiga de escárnio satiriza alguém por meio de equívocos verbais e que a de maldizer, por meio de palavras claras, na Lei XXX do Título IX da "Partida Segunda", Afonso X prescreve uma atividade cortesã, que coincide com a natureza do gênero satírico, considerando o que nele deve prevalecer: palavras adequadas para a cantiga escarninha, ou seja, palavras e versos (não nos esqueçamos de que um dos sentidos de palabra é verso em galegoportuguês, como nos lembra Montoya Martínez ${ }^{31}$ ) que propiciem o humor e a diversão, sem ofensa para os visados da corte. Não é apenas o recurso retórico, equivocatio, ${ }^{32}$ em sentido estrito, que está em pauta, mas seu fundamento, além da necessidade de se produzirem cantigas bem talhadas, com tema desenvolvido argutamente (com equívocos tanto no sentido estrito [textual] como no geral [contextual]) e com a finalidade eminente, a princípio, de entretenimento.

30 "Cantigas d'escarneo som aquelas que os trobadores fazen querendo dizer mal d'alguen en elas, e dizen-lho per palavras cubertas que hajan dous entendimentos, pero lhe-lo non entenderen... ligeiramente: e estas palavras chamam os clérigos "hequivocatio" (...) Cantigas de maldizer son aquela $<$ s $>$ que fazem os trobadores <contra alguem $>$ descubertamente: $\mathrm{e}<\mathrm{m}>$ elas entraram palavras $\mathrm{e}<\mathrm{m}>$ que queren dizer mal e nom aver $<\mathrm{am}>$ outro entendimento se non aquel que querem dizer chãam<ente> (...)" (ARTE, 1999, p. 42). ${ }^{31}$ MONTOYA MARTÍNEZ, 1989, p. 441.

32 Serxio Otero González examina o conceito de cantiga de escárnio, afirmando que a noção de equívoco não é suficiente para defini-la. Completa-a a noção de alegoria, uma vez que a decodificação das cantigas requer uma leitura do conjunto de elementos metafóricos para serem compreendidas. Afirma o autor que "[as cantigas escarninhas] têm uma função lúdica e que o processo de codificação e descodificação que se detecta nestas brincadeiras ultrapassa pela sua complexidade a do simples 'hequivocatio'” (OTERO GONZÁLEZ, 2005, p. 85 e p. 101). 
É certo que a sátira ocupava um lugar destacado nos seróes palacianos, seja pela grande produção dos trovadores (388 cantigas de 65 trovadores $^{33}$ ), seja pela própria produção do Sábio $\left(40\right.$ cantigas $\left.^{34}\right)$, seja ainda pelo destaque dado ao assunto em suas leis. Não menos evidente é a natureza desestabilizadora do maldizer, oscilante entre o jogo e o crime, que requeria certo controle na produção de homens interessados em divertir uma corte por meio de cantigas que contrabalançassem o desejo de dizer/denunciar/ divertir e a adequação palaciana exigida por lei, sim, mas, antes ainda, pelos costumes dos homens polidos. Ambas as ações, entretenimento e crime, dependiam, como se observou, da intenção do escarnecedor e da interpretaçăo do escarnecido. A concepção de diversão cortesã era amparada pela noção de jogo, uma vez que "El juego, en tanto relación compartida y unánimemente aceptada por los participantes, borraba el efecto injurioso". ${ }^{35}$

Cotejando o que dizem as Partidas, o que surge no verso das cantigas e o que afirmam os pesquisadores, deduz-se com certa facilidade que provavelmente havia dois tipos de alvo para o jugar de palabra. Sendo um presumível rex facetus, ${ }^{36}$ Afonso X regia sua corte e o fablar en gasaiado,

${ }^{33}$ Entre 1240 e 1300, foram produzidas 568 cantigas de amor por 72 trovadores, e 471 cantigas de amigo por 79 trovadores (OLIVEIRA, 2001, p. 164).

${ }^{34}$ A despeito do que supóem os especialistas a respeito do período mais intenso de produção de cantigas de Afonso X, provavelmente em sua juventude (BALLESTEROS BERETTA, 1984, p. 249; CÁRDENAS, 1990, p. 249). Manuel González Jiménes, por sua vez, afirma que "Las cantigas profanas atribuidas a Afonso X cubren todo su reinado, aunque buena parte de ellas se enmarcan cronológicamente en los años iniciales de su reinado (1252-1266)” (GONZÁLEZ JIMÉNES, 2004, p. 435).

35 MADERO, 1992, p. 38.

${ }^{36}$ Sobre o rex facetus, afirma Jacques Le Goff a propósito de Henrique II: "Par la plaisanterie distillée par le roi et circulant dans le cercle, la collectivité des participants à la curia royale, Henri II a attaché à la couronne ce groupe de rieurs et a fait des nobles indisciplinés des courtisans apprivoisés par le rire en commun suscité par le roi. Mais cette cour rieuse utilize aussi le rire 
levando em conta os rumos históricos (de que são testemunhos os cantares sobre a traição dos vassalos na guerra contra Granada) e as relações políticas de seu reino. ${ }^{37}$ Assim sendo, o tratamento dado aos inimigos - certamente fora de sua corte ou enrustidos em sua presença ${ }^{38}$ - poderia ou não implicar na menção direta e na crítica explícita "sobre aquella cosa que fuere en aquel lugar a quien jugaren", ou seja, nos juegos da cantiga poderiam subjazer, como nas cantigas morais e sirventeses, saña e tristeza talvez.

Dadas essas circunstâncias, evidencia-se o oposto do que a crítica moderna parece inclinada a ver na literatura e, em particular, na sátira: $o$ contra-poder. ${ }^{39} \mathrm{~A}$ sátira, tanto quanto os outros produtos literários medievais peninsulares, seria inequivocamente oficializada pelo rei. ${ }^{40}$

Como se percebe, detectar o sentido lúdico ou lúdico-político das cantigas depende da informação que se tenha dos envolvidos no jugar de palabras, o trovador, o visado e sua época. Parece evidente, no entanto, que para os da afinidade e convívio leal do rei, o trovador dispunha do jogo do avesso, do equívoco para surtir surpresa e gargalhada..$^{41}$ Para os escárnios e sobre estes é que a lei parece ajustar-se especialmente e para a qual deviam adequar-se os trovadores. Assim, o mais importante seria compor bem cada

comme une arme pour ruiner la corrière de tel ou tel puissant ou candidat à la sphère supérieure. Rire d'un membre de la cour peut être mortel" (LE GOFF, 1997, p. 452).

${ }^{37}$ Algumas cantigas de outros trovadores denunciam a preocupação política, como a de João Soarez de Paiva, "Ora faz ost' o senhor de Navarra", ou de Afonso Mendez de Besteiros, "Já lhi nunca pediran". (Cf. PAREDES NÚNEZ, 2004; BELTRAN, 2005).

${ }^{38}$ Lembre-se que as relações políticas entre Afonso $\mathrm{X}$ e os nobres eram tensas, especialmente a propósito da promulgação das Partidas, cuja linha jurídica cerceava os poderes dos senhores peninsulares. Cf. O'Callaghan (2001, p. xxxix) e Palacios Alcaine (1991, p. xiv).

39 DOBARRO PAZ, 1990, p. 102.

${ }^{40}$ BARROS, 2006, p. 54.

${ }^{41}$ Como aconselha a Retórica antiga (ALBERTI, 1999, p. 59). 
tipo de texto e apresentá-lo em seu devido momento e lugar. Cada um seria resultado (cantigas de amor, cantigas de amigo, cantigas de escárnio e maldizer, os mais conhecidos) de um grande jogo de corte, ${ }^{42}$ em que homens idealizavam uma dona arrogante; moças aguardavam o amigo, para saciarem seu desejo, e bem humorados escolhiam e alardeavam as mazelas fictícias, avessas ou "verdadeiras" de alguém, para a encenação e performance no fablar en gasaiado.

Se na Arte de trovar as cantigas de escárnio e maldizer aparecem como gêneros de igual valor, ou seja, não são reduzidas a outros gêneros em que "sabedoria nem outro bem haja" (risabelha), percebe-se, no cotejo entre as leis que regeriam a prática do cotidiano e as leis que regeriam a prática poética uma diferença: na lei da conveniência social, o valor do jogo equívoco das situaçóes, dos rasgos morais dos freqüentadores da corte em gasaiado, que garantisse a competência de sociabilidade palaciana; na lei da convivência poética, o equívoco de palavras ${ }^{43}$ e o obsceno em talhos de cantigas que garantissem competência literária cortesã, como é o caso dos famosos equívocos da "maeta descadeada" (em "Maria Pérez, a nossa cruzada", de Pero da Ponte) ou da "midida de Espanha" (em "Joan Rodríguiz foi osmar a Balteira”, de Afonso X).

42 "La lírica medieval tiene mucho de juego, tanto en su forma como en su fondo. El debate, la burla, el dicterio, donde el poeta se servía del doble sentido de las palabras para escamotear el verdadero sentido de su mensaje, se conjugaba perfectamente con el juego pomposo que suponían las canciones amorosas, donde los consabidos personajes jugaban entre sí. La dama haciéndose la esquiva, el amante fingiéndose desolado; ambos resaltando su temor de ser descubiertos por el celoso, por el envidioso. Todas cuantas soluciones se puedan pensar como salidas de este juego aristocrático no son sino otros tantos resultados del esquema, lúdico ya en su esencia, del consabido amor trovadoresco, cantado en tantas y tantas cortes europeas (MONTOYA MARTÍNEZ, 1991, p. 369).

${ }^{43}$ José Luiz Rodriguez examina o equívoco e os diversos processos nele envolvidos: dilogia, jogo de palavras, calembur e dissociação (1976, p. 37 et seq.). 
Dentre as inúmeras, destaco uma pergunta pontual para o que propõe basicamente este trabalho: se as Partidas foram produzidas provavelmente entre 1256 e 1265, se seus antecedentes imediatos, Especulo, Fuero real e Setenário, são provavelmente de 1255, e, ainda, se estiver correto Beltran em situar o encontro entre João Soares Coelho, Sordello e seu jogral Picandon entre 1231 e 1232, que relação poderia haver entre o que prescrevem os códigos jurídicos afonsinos e a tenção do trovador português?

\section{Referências}

ALFONSO X. Espéculo. Edición de Robert A. MacDonald. Madison: Universidad de Richmond, 1990.

AFONSO X El Sabio. Fuero real. Edición de Azucena Palácios Alcaine. Barcelona: Promociones y Publicaciones Universitarias, 1991a.

AFONSO X. Fuero real. Edição de José de Azevedo Ferreira. Braga: Universidade do Minho, 1982. 2 v.

ALFONSO X. Las siete partidas. Edição fac-similada da edição salmantina de 1555, glosada por Gregorio Lopez e impressa por Andrea de Portonariis. Madrid: Boletín Oficial del Estado, 2004. 3 v.

ALFONSO X. Las siete partidas. Translation by Samuel Parsons Scott. Edition by Robert I. Burns. Pennsylvania: University of Pennsylvania, 2001. 5 v. v. I-II. ALFONSO X. Las siete partidas: antología. Selección de Francisco López Estrada y María Teresa López García-Berdoy. Madrid: Castalia, 1992.

ALFONSO X. Partida Segunda de Alfonso X el Sabio. Manuscrito 12794 de la BN. Edición de Aurora Juarez Blanquer y Antonio Rubio Flores. Granada: Ácaro, 1991b.

ALFONSO X. Setenario. Edición de Kenneth H. Vanderford. Buenos Aires: Universidad de Buenos Aires, 1945.

BALLESTEROS BERETTA, Antonio. Alfonso X el Sabio. Barcelona: El Albir, 1984. Cap. VI: Las cortes de Toledo del año 1259, p. 213-253; Cap. VIII: Niebla y Cadiz, p. 296-361. 
BARROS, José D’Assunção. Afrontando o rei através da poesia - Um estudo sobre as lutas de representações entre os trovadores medievais-ibéricos dos séculos XIII e XIV. História e Perspectivas, Uberlândia, n. 34, p. 49-82, 2006.

BELTRÁN, Vicenç. El rey sabio y los nobles rebeldes. La poética del escarnho. In: ENCONTRO INTERNACIONAL DE ESTUDOS MEDIEVAIS DA ABREM, 3., Rio de Janeiro, 1999. Anais.. Rio de Janeiro: Ágora da Ilha, 2001. p. 31-58.

BELTRÁN, Vicenç. La corte de Babel: lenguas, poética y política en la España del siglo XIII. Madrid: Gredos, 2005.

BURNS, Robert I. The Partidas: Introduction. Introduction to the First Partida. In: ALFONSO X. Las siete partidas. Translation by Samuel Parsons Scott. Edition by Robert I. Burns. Pennsylvania: University of Pennsylvania, 2001. 5 v. v 1. p. ix-xxix; p. li-lviii.

CORREIA, Ângela. As cantigas de amor de D. Joam Soares Coelho e o "ciclo da ama": edição e estudo. Lisboa, 2001. Dissertação [Tese] (Doutorado em Literatura Portuguesa) - Faculdade de Letras, Universidade de Lisboa. 2001.

DIOGO, Américo António Lindeza. Leitura e leituras do escarnh' e maldizer. [s. 1.]: Associação Portuguesa de Pais e Amigos do Cidadão Deficiente Mental, 1998.

DOBARRO PAZ, Xosé María. Moral e política nos cancioneiros. In: BANEIRO BANEIRO, X. L. (Ed.). O pensamento galego na história. Santiago de Compostela: Universidade de Santiago de Compostela, 1990. p. $95-102$.

LANCIANI, Giulia; TAVANI, Giuseppe. As cantigas de escarnio. Tradução de Silvia Gaspar. Vigo: Xerais de Galicia, 1995.

LAPA, Manuel Rodrigues (Ed.). Cantigas d'escarnho e de maldizer dos cancioneiros medievais galego-portugueses. 3. ed. ilustrada. Lisboa: João Sá da Costa, 1995.

LIU, Benjamin. Medieval Joke Poetry: the cantigas d'escarnho e de mal dizer. Cambridge (Massachusetts): Harvard University, 2004.

LOPES, Graça Videira (Ed.). Cantigas de escárnio e maldizer dos trovadores e jograis galego-portugueses. Lisboa: Estampa, 2002. 
LOPES, Graça Videira. A sátira nos cancioneiros medievais galego-portugueses. Lisboa: Estampa, 1994.

M. MÉRIDA, Rafael. D’ome atal coita nunca vi cristão: amores nefandos en los trovadores gallego-portugueses. In: BREA, Mercedes (Coord.). O cantar dos trobadores. Santiago de Compostela: Xunta de Galicia, 1993. p. 433-437.

MADERO, M. Manos violentas, palabras vedadas: la injuria en Castilla y León (siglos XIII-XV). Madrid: Taurus, 1992.

MAGNE, Augusto. Glossário da Demanda do Santo Graal. Rio de Janeiro: Instituto Nacional do Livro, 1967. 3 v. v. III.

MENÉNDEZ PIDAL, Ramón. Poesía juglaresca y juglares. Madrid: EspasaCalpe, 1991.

MONTOYA MARTÍNEZ, Jesús. Caracter lúdico de la literatura medieval (A propósito del 'jugar de palabra'. Partida Segunda, tít. IX, ley XXIX). In: CASTILlO, C. Argente del et al. (Rec.). Homenaje al Profesor Antonio Gallego Morell. Granada: Universidad de Granada, 1989. p. 413-442.

O'CALLAGHAN, Joseph F. Alfonso X and the Partidas. In: ALFONSO X. Las siete partidas. Translation by Samuel Parsons Scott. Edition by Robert I. Burns. Pennsylvania: University of Pennsylvania, 2001. 5 v. v. I. p. xxx-xl.

O'CALLAGHAN, Joseph F. El Rey Sabio. El reinado de Alfonso X de Castilla. Sevilla: Universidad de Sevilla, 1999. Introducción, p. 21-24; Cap. 9: Literatura y vida intelectual, p. 169-187; Cap. 17: El rey Sabio: p. 320-332.

OTERO, Alfonso. Las Partidas y el Ordenamiento de Alcalá en el cambio del ordenamiento medieval. Anuario de Historia del Derecho Español, Madrid, t. LXIII-LXIV, p. 451-547, 1993-1994.

OTERO GONZÁLEZ, Serxio. Alegorias na “cantiga de escarnho” galegoportuguesa: uma aproximação. In: SANMARTÍN BASTIDA, Rebeca; VIDAL DOVAL, Rosa (Ed.). Lãs metamorfosis de la alegoría: discurso y sociedad en la Península Ibérica desde la Edad Media hasta la Edad Contemporánea. Madrid: Iberoamericana/Vervuert, 2005. p. 83-103.

PAIS, Marco Antonio de Oliveira. A lírica galego-portuguesa nos séculos XIII$X I V$ : realidade histórica e inversão. 1990. 421 f. Tese (Doutorado em Antroploxía Social) - Universidade de Santiago de Compostela, Santiago de Compostela, 1990. 
PALÁCIOS ALCAINE, Azucena. Fueros medievales y sus problemas. Obra legislativa de Alfonso X. El Fuero real. In: AFONSO X El Sabio. Fuero real. Edición de Azucena Palácios Alcaine. Barcelona: Promociones y Publicaciones Universitarias, 1991. p. i-xxxviii.

PAREDES NÚNEEZ, Juan. Las cantigas profanas de Alfonso X el Sabio (temática y classificación). In: CARMONA, Fernando; FLORES, Francisco J. (Ed.). La lengua y la literatura en tiempos de Alfonso X. Murcia: Universidad de Murcia, 1985. p. 449-466.

PRESILLA, Maricel E. Conflicts between ecclesiastical and popular culture in the Cantigas de Santa Maria. Romance Quaterly, Kentucky, v. 33, n. 3, p. 331-342, aug. 1986.

VAN SCOY, Herbert Allen. A Dictionary of Old Spanish Terms Defined in the Works of Alfonso X. Madison: Hispanic Seminary of Medieval Studies, 1986. VENTURA, Joaquim. Sátira e aldraxe entre trobadores e xograis. In: BREA, Mercedes (Coord.). O cantar dos trobadores. Santiago de Compostela: Xunta de Galicia, 1993. p. 533-550. 


\section{Resumo}

Investiga a tenção "Vedes, Picandon, soo maravilhado", de João Soares Coelho, trovador português, e Picandon, jogral do trovador lombardo Sordello, ambos do século XIII - conhecida por sua explícita referência a um "jogo" de maldizer entre os dois poetas -, considerando sua possível relação com o jugar de palabra, isto é, o trovar satírico prescrito por Afonso X na Lei XXX ("Quantas cosas deven ser catadas en el retraer”) do Título IX (Qual deve el Rey ser a sus officiales, e a los de su casa, e de su corte, e ellos a el) da Segunda de Las siete partidas. Aborda aquele conceito a partir do que prescreve a Arte de trovar sobre as cantigas de escárnio e maldizer, e do que discute o crítico Jesús Montoya Martínez acerca da sátira galegoportuguesa e de sua regulamentação jurídica medieval peninsular.

\section{Abstract}

Investigation on the tenção "Vedes, Picandon, soo maravilhado", by João Soares Coelho, Portuguese troubadour, and Picandon, Lombard Sordello jongleur, both from XIII ${ }^{\text {th }}$ - a song known specially by its explicit reference to a joke of "maldizer" between the two poets -, observing its possible relation with the jugar de palabra, the satiric trobar prescribed by Afonso X in "Lei XXX" ("Quantas cosas deven ser catadas en el retraer") do Título IX (Qual deve el Rey ser a sus officiales, e a los de su casa, e de su corte, e ellos a el) in the Second of Las siete partidas. Discussion about that concept considering what the Arte de trovar regulates about "cantigas de escárnio e maldizer", and Jesús Montoya Martínez studies about Galician-Portuguese satire and its Medieval Peninsular juridical rules. 